\title{
External Drivers and Internal Control Factors that Determine the Vulnerability and Response Capacity to Drought of Cattle Producers in the Sierras Del Este Region of Uruguay
}

\author{
Ismael Díaz ${ }^{1}$, Marcel Achkar ${ }^{1} \&$ Nestor Mazzeo ${ }^{2}$ \\ ${ }^{1}$ Laboratorio de Desarrollo Sustentable y Gestión Ambiental del Territorio, Instituto de Ecología y Ciencias \\ Ambientales, Facultad de Ciencias, Universidad de la República, Uruguay \\ ${ }^{2}$ Departamento de Ecología y Evolución, Centro Universitario Regional Este, Facultad de Ciencias, Universidad \\ de la República, Uruguay \\ Correspondence: Laboratorio de Desarrollo Sustentable y Gestión Ambiental del Territorio, Instituto de Ecología \\ y Ciencias Ambientales, Facultad de Ciencias, Universidad de la República, Uruguay. E-mail: \\ idiaz@fcien.edu.uy
}

Received: October 23, 2017

Accepted: November 24, 2017

Online Published: December 15, 2017

doi:10.5539/jas.v10n1p190

URL: https://doi.org/10.5539/jas.v10n1p190

\begin{abstract}
Increased response and adaptation capacity are key elements for coping with climate threats. Cattle producers in the Sierras del Este region are one of several groups that are the most vulnerable to climate variability in Uruguay. Despite this commonality, it is a heterogeneous system, which suggests that strategies to respond to these events are divergent. The objective of this work is to identify and evaluate the vulnerability of cattle producers to drought and determine drought response strategies. A new approach is proposed and focuses on the identification of differential capacities to address the vulnerabilities. In addition, this approach seeks to define groups of similar producers of vulnerability since the design of public policies cannot be developed in isolation. For evaluation, we provided consultations with livestock producers and specialists from which we collected our data. Data was analysed using multivariate statistical analyses. Our results indicated that $69 \%$ of the system's vulnerability variance can be explained by 4 components: the capacity for cattle management, the socio-economic capacity to handle drought, the capacity to generate alternatives to cattle feeding, and the commercial and financial flexibility of the producers. These findings also yielded response groups that, in turn, identified 7 producer groups with significant differences in the available and necessary capacities to respond to drought. This methodological strategy allowed the operationalization of the vulnerability and responsiveness concepts, and the identification of strategies for these events. Additionally, this strategy creates an understanding of the complexity of the system and the variables that contribute to it.
\end{abstract}

Keywords: drought, vulnerability, response capacity, climate variability, rangelands, livestock

\section{Introduction}

Rio de la Plata's grasslands represent one of the largest areas of sub-humid natural grasslands in the world $\left(700,000 \mathrm{~km}^{2}\right)$, distributed over a portion of territories in Argentina, Brazil, and Uruguay (Soriano, 1991). A sub-humid mild climate, with highly fertile soils and gentle slopes, has made it possible for an extensive cattle industry to be one of the most important economic activities of the region since the 18th century.

In Uruguay, an extensive cattle industry is one of the principal agricultural activities, considering its size (more than $75 \%$ of the country's agricultural surface), number of producers and agricultural establishments (more than $80 \%$ of the country's total) (DIEA, 2011), and share in exports (more than $29 \%$ of the total exports) (DIEA, 2016). Even though the Uruguayan climate is mild and humid, the most important meteorological threat is the occurrence of agronomic droughts (Cruz et al., 2014). The economic losses of the last droughts that occurred in 2006, 2008, 2009, and 2015 exceeded hundreds of millions of dollars (OPYPA, 2009, 2016).

Family producers of cattle perform their activity only in natural grasslands and are particularly vulnerable to drought events due to their land tenure system, the surface they manage, their characteristics, and their production strategies, such as grazing in natural grassland, the absence of irrigation systems, low forage and fodder production and limited access to alimentary complements. 
For the implementation of more efficient policies, Uruguay's agricultural institutions have determined two priority regions according to their high vulnerability to climate change and variability. These two regions have been defined by some priority, livestock producers and a set of geophysical attributes: soil types and surface slopes. The delimitation of the two regions is due to a partial definition of vulnerability and is elaborated from few variables. In addition, this definition made vulnerability difficult to assess within the current vulnerability assessment frameworks.

\subsection{Vulnerability Assessment}

Vulnerability studies are the logical starting point for decision makers wishing to develop plans to reduce drought vulnerability and generate response strategies (Moser \& Ekstrom, 2010). Vulnerability studies have been approached from various disciplinary fields (e.g., geography, ecology, climatic sciences), and in the last decade, they have been transformed into an emergent concept for climate sciences, increasing their theoretical development (Cardona, 2003; Füssel \& Klein, 2006). The theoretical framework and the definition adopted by The Intergovernmental Panel on Climate Change (IPCC) (McCarthy et al., 2001) have had important repercussions on the international scientific community and its definitions have been largely accepted. The IPCC defines vulnerability as 'The degree to which a system is susceptible to, or unable to cope with, adverse effects of climate change, including climate variability and extremes. Vulnerability is a function of the character, magnitude, and rate of climate variation to which a system is exposed, its sensitivity and its adaptive capacity'. The fundamental attributes of this definition are; exposure: 'The nature and degree to which a system is exposed to significant climatic variations'; sensitivity: 'the degree to which a system is affected, either adversely or beneficially, by climate-related stimuli'; and adaptive capacity: "the ability of a system to adjust to climate change to moderate potential damages, to take advantage of opportunities, or to cope with the consequences" (McCarthy et al., 2001). For that matter exposure is considered as a system driver while sensitivity and adaptive capacity as internal attributes (Füssel \& Klein, 2006).

The diversity of epistemological approaches and disciplines involved has determined different approaches for the evaluation of vulnerability (Luers, 2005; Füssel 2007; Gallopín, 2006; Soares et al., 2012). The general trend in vulnerability assessments has been a transition away from the identification of potential impacts and is now oriented towards the implementation of mitigation measures for defining and prioritizing the location of resources for the execution of adaptation strategies (Füssel \& Klein, 2006). In addition, there have been increases in the scale of the analysis, the consideration of non-climatic factors, multidisciplinary approaches, and the promotion of a larger involvement from beneficiaries in the evaluation process.

Currently, most evaluations focus on the definition made by Mc Carthy et al. (2001), and deepened by Chapin et al. (2009). These frameworks have been considered in numerous quantitative vulnerability assessments produced for diverse systems, such as the generation of the vulnerability indexes (i.e.: Adger, 2006; Füssel \& Klein, 2006; Hahn et al., 2009; Sullivan, 2011; Aryal et al., 2014). Quantitative approaches have been the most common as they enable an easier interpretation and provide clarification regarding the contribution of socioeconomic and biophysical factors. Additionally, quantitative approaches are useful for monitoring and studying trends and are applicable to diverse spatial and temporal scales (Gbetibouo \& Ringler, 2009). Moreover, it allows for the analysis of the spatial and temporal variability of variables that make up the defined model and the groups and areas with high vulnerability values (Pandey, 2010).

In general, vulnerability assessments have enabled adaptation plans that do not consider the diversity of social situations within a region (Andersen et al., 2007). Grouping is a very useful way of representing diversity and an opportunity to design policies for the full range of producers ( Marshall \& Smajgl, 2013; Marshall et al., 2014).

\subsection{Drought Vulnerability Assessment}

In the last decade, the understanding of the drought phenomena and its evaluation has become more complex as the drought phenomenon constitutes a multidimensional problem that exceeds the climate dimension and is conditioned by numerous controls involving physical, social, productive, and economic attributes (Blaikie et al., 1994). In addition, the impact of droughts in different productive areas and population groups is differential and spatially complex, according to biophysical, social, and productive differences in each area (Downing \& Bakker, 2000; Wilhelmi \& Wilhite, 2002).

Worldwide, the most common approaches for assessment resort to integration and aggregation of variables for the conformation of sub-indices, which are subsequently added to a general vulnerability index. The integration of variables has oscillated between the consideration of equal weight in the variables, the weighting by academic experts or the local population, and the use of multivariate statistical methods (Wilhelmi \& Wilhite, 2002; Pandey, 2010; Zarafshani et al., 2012; Antwi-Agyei et al., 2012). 
Through these methodologies, areas have been identified with larger relative vulnerabilities and variables with higher incidence. This information has been useful for defining the principal orientation of adaptation measures on a large scale. However, these approaches cannot obtain the level of detail required to identify, on a local scale, the behaviour of each variable of each group and each place in particular, principally in relatively homogeneous areas and with relatively homogeneous cattle producers (O'Brien et al., 2004; Antwi-Agyei et al., 2012). This emphasizes the need for multiscalarity and a move towards large-scale analysis.

Thus, the assessment of the incidence of each variable requires a more detailed approach, allowing the identification of differences within a relatively homogeneous context. This situation is particularly relevant in the assessment of the family farmers' vulnerability to drought in the eastern region of Uruguay, and the following questions arise: what socio-ecological factors and attributes determine the vulnerability of family farmers to drought? How are the factors and attributes prioritized by producers grouped? Are they grouped by dimension or by the classic components of vulnerability? Using the producer identified factors and attributes, what is the evaluation of the state of the situation? What is the relationship between the factors and attributes prioritized and the state of situation? Is the target group an appropriate operational unit for current public policies and programs? As a result, the objective of this work was to identify and assess the variables that determine the cattle producers' vulnerability to drought and to determine the main response strategies.

\section{Materials and Methods}

\subsection{Study Area}

The study area is delimited by Barriga Negra and Polanco stream basins, presenting an approximate surface of 72600 ha. It is located in the region of Sierras del Este, Uruguay, between $33^{\circ} 50^{\prime}$ and $34^{\circ} 11^{\prime}$ south latitude and between $54^{\circ} 60^{\prime}$ and $55^{\circ} 19^{\prime}$ west longitude (Figure 1). Dominant soils are of medium fertility, slopes vary from moderate (5\%) to strong (more than 15\%) and natural grasslands are the ecosystem with the greater surface.

In this area are located approximately 100 producers who develop livestock activity mostly on natural grasslands. The medium extent of the properties is 150 ha, registering producers with less than 20 ha and producers with more than 1300 ha. The majority of the producers develop a mixed cattle industry (bovine and ovine), more than $30 \%$ of the producers do not reside in cattle fields permanently and a considerable number of producers carry out other economic activities besides cattle industry, principally as employees in different agricultural establishments. The principal demographic characteristics of producers are: an average age superior to 50 years, a middle socioeconomic level and a high index of males.

Surface destined for the cattle industry has decreased in the last decades due to the advance of exotic forest. This advance has been promoted by the implementation of agricultural policies that stimulated the growth of large monocultures (principally exotic forest and oleaginous), which has consolidated a crucial process of agricultural intensification in Uruguay. Even though $70 \%$ of the area under study is located in a priority forest area defined in Uruguayan legislation, more than $73 \%$ of the area is destined to extensive cattle industry.

Sierras del Este region has been identified at government level as one of the most vulnerable to drought zones because of its physical characteristics (slopes and soils) and productive (smallholders) (MGAP, 2012). Over the last decade an important set of public policies has benefited several cattle producers in the area. Among those that stand out are "Plan Ganadero", "Proyecto de Producción Responsible", "Plan de Apoyo a la Cría Vacuna", "Plan Ovino and Plan de Producción Familiar", through DGDR-MGAP. 


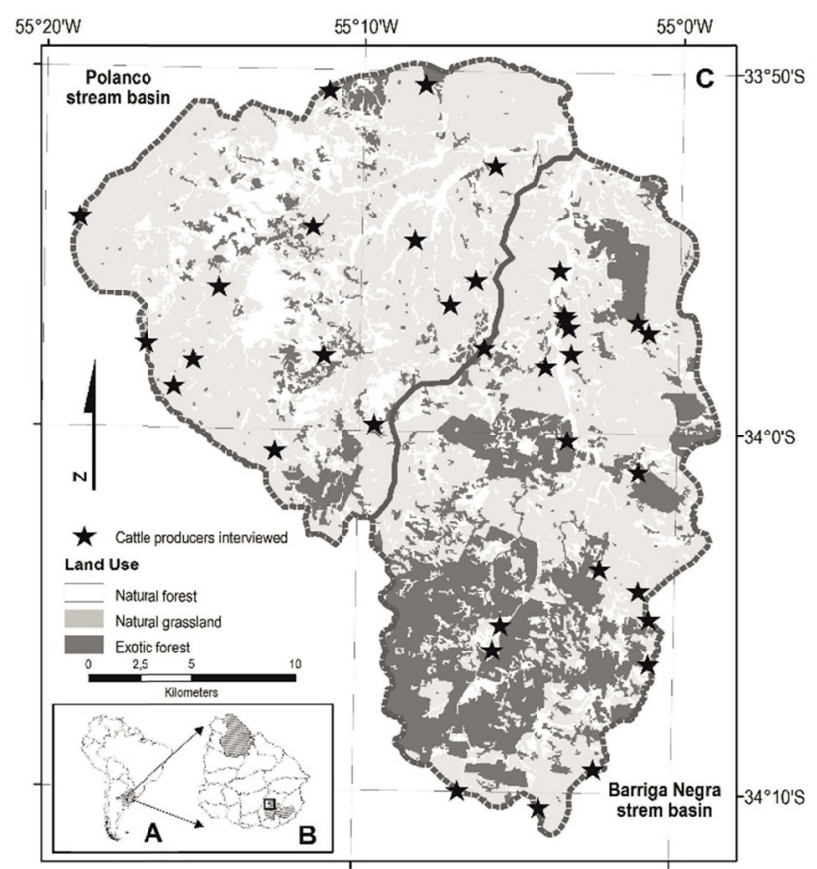

Figure 1. Study area. A. Pampas Biome. B. Zone of high vulnerability to climate change in Uruguay for cattle family producers sector. C. Dominant land cover and localization of interviewed producers

\subsection{Research Strategy}

Our investigation is based on that the process of identifying actions and responses to threats is crucial for planning and management at various scales (local, regional and national). Vulnerability, exposure, and sensitivity are differential according to the zone and/or population group being examined, and thus the adaptation and response strategies must be different. Therefore, we proposed an evaluation of the totality of the variables that affect vulnerability and analysed the set of responses necessary to address the vulnerability, at local and regional scale. This proposed approach focused on the identification of the differential capacities necessary to confront vulnerability and not on a quantification of vulnerability.

Our strategy included the identification of the factors that determine vulnerability to drought, the assessment of their relevance, and the definition of groups of producers with similar assessments (Figure 2).

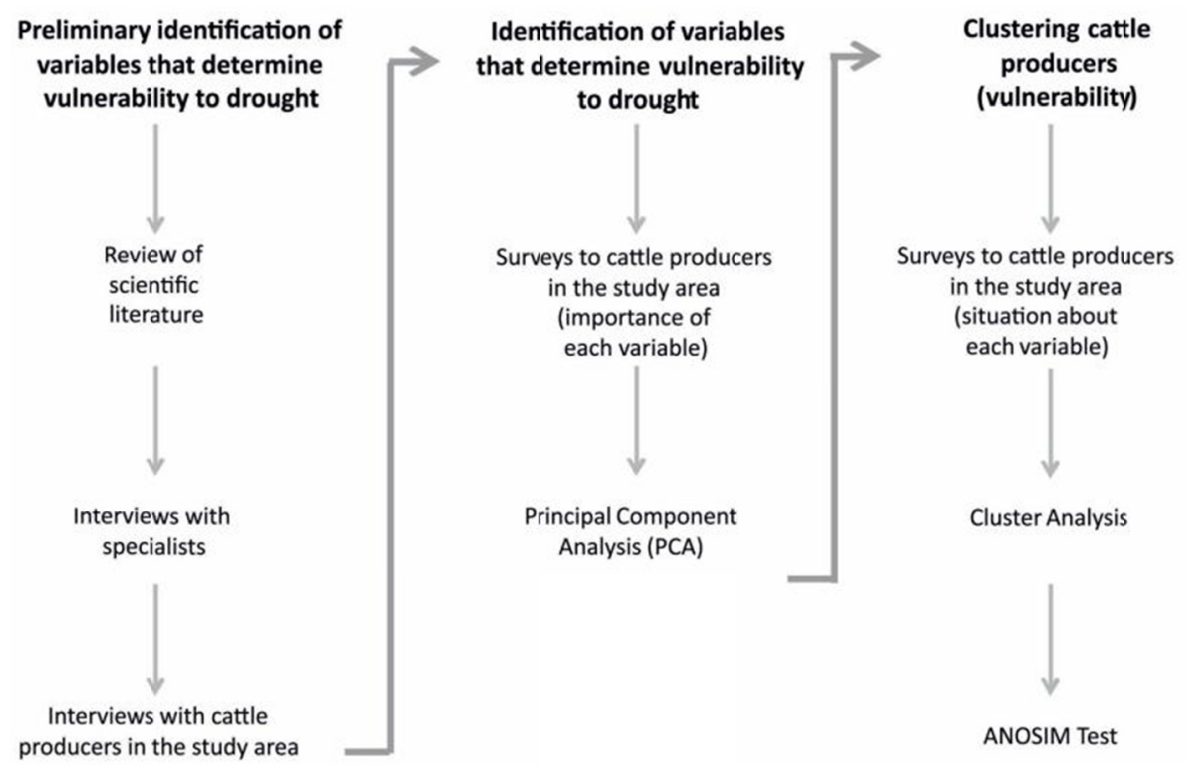

Figure 2. Investigation strategy scheme: stages/phases (bold font) and methods used 


\subsection{Data Collection Methods}

Through the revision of the scientific bibliography, the data collection was identified as a set of external drivers and internal controls that had a potential impact on drought vulnerability. Forty-five variables were identified with associations with the biophysical, socio-economic, cultural, productive, and financial dimensions. These variables were associated with the livestock producers' vulnerability to drought in different climatic and geographic regions. This variable set was analysed by 10 local producers of the study area and 5 local specialists in agricultural sciences and geography. The final set of variables that were associated with an impact on vulnerability to drought for cattle producers in the region were reduced to 34 .

The set of principal drivers to the system was represented by climatic variables (rainfall and evapotranspiration) and land-use. Due to the dimension of the study area and its physical characteristics (altimetry), it was possible to assume that there were no significant differences in biophysical exposure within the study area. On the other hand, the incidence of changes in soil use was expressed through the expansion of exotic forest on cattle lands, which generated a reduction of natural grassland surface and an increase in the cost of land. This pressure had been extended to the entire study area, determining that the increase in the price of land did not present significant differences in the basins analysed, and the differences in the difficulty of accessing new lands was not significant. The behaviour of this set of variables (exposure) was considered constant, and as a result, they were not included in the analysis.

The following stage included the survey of the 34 variables of each cattle producer, performed through semi-structured interviews. Initially, the cattle producers were consulted on the importance they assigned to each variable. Secondly, the situation in which each producer was related to regarding that variable was highlighted. Finally, the producers were consulted on the feasibility to take the necessary actions to address the variables identified. A valuation between 1 and 5 was chosen for each variable; 1 meaning less important (or a critical situation) and 5 meaning very important (or a very favourable situation). At this stage, 35 cattle producers were consulted, which represented more than $50 \%$ of the producers who carry out their productive activities and reside permanently in the study area.

As a result of this entire process, two $34 \times 35$ data matrices were generated. The first matrix refers to the importance of each variable (matrix of importance). The second matrix refers to the situation of each producer in regards to that variable (matrix of the situation).

\subsection{Data Analysis}

The data analysis stage integrated the multivariate exploratory methods and the multivariate hypothesis tests.

To identify the most relevant variables in the explanatory model of vulnerability to drought, multivariate exploratory techniques were utilized. These techniques have been widely used in various disciplinary fields and have been applied recently to vulnerability analysis (Abson et al., 2012) and risk (Gazzano et al., 2015). A similar approach to that used by Usai et al. (2006), and Marshall et al. (2014) was implemented, initially using principal component analysis (PCA) for the identification and grouping of variables and later using cluster analysis (CA) for the grouping of producers.

PCA is a powerful data exploration tool that allows converting a series of correlated variables into a minor set of uncorrelated variables that capture the variability of the data. The variable identification process was carried out using the matrix of importance. While selecting the components, it was taken as general criteria that each component had an Eigen value greater than 1 and a variance greater than $5 \%$.

From the components and variables identified, CA was performed to continue the implementation of exploratory methods. In this case, the purpose was to determine groups of producers with dissimilarity in their situation regarding the variables that determine vulnerability to drought. Cluster methods allowed the identification of groups of individuals, where the homogeneity between groups and the difference with other groups is maximized. In this way, the grouping of producers was carried out according to the situation values (matrix of the situation), in variables identified by PCA for the importance matrix values. The cluster analysis process was based on the nearest centroid sorting method (Anderberg, 1973) used by Usai et al. (2006).

Subsequently, the ANOSIM test was performed to determine if the differences between the groups identified were statistically significant. The ANOSIM test is a non-parametric test that evaluates the significance of the difference between the values of two or more groups by measuring the distance of the values of their matrices of (dis)similarity (Clarke, 1993). As a method, the Euclidean Distance with the Bonferroni correction with 9999 iterations was used. 
R software, version 2.12.2 (R-Team 2012) was used in the data analysis. In all statistical tests, a significance level of 0.05 was established.

\section{Results}

\subsection{Variables and Attributes that Condition Vulnerability}

The integration of the bibliographic review with the interviews of local specialists and cattle producers resulted in the identification of 34 variables with a potential impact on the vulnerability of producers to drought (Table 1).

Table 1. Preliminary list of variables that affect cattle producers' vulnerability to drought

\begin{tabular}{ll}
\hline Biophysical variables & $\begin{array}{l}\text { natural grassland productivity, soils, availability of arable land to produce fodder, soil degradation, natural } \\
\text { forest, slope, access to water }\end{array}$ \\
$\begin{array}{l}\text { Economical variables } \\
\text { farm incomes, availability of other incomes, possibility to access to productive credits, availability of } \\
\text { savings, establishment's size, tenure system, prices (buy/sale), dependence on livestock activity, commercial } \\
\text { flexibility for purchase and sale of cattle, investments in the establishment }\end{array}$ \\
$\begin{array}{l}\text { pariables } \\
\text { producer association, strong commercial links with nearby producers, experience in the activity, experience } \\
\text { in drought, trust in neighbour producers, distrust in neighbour producers }\end{array}$ \\
$\begin{array}{l}\text { Productive variables } \\
\text { livestock stocking level adjustment, access to supplements and rations, possibility of leasing land at critical } \\
\text { timticipate the severity of drought, access to technical assistance, capacity of savings for investing in the } \\
\text { establishment, availability of aid in times of crisis, public policies access, sheep/bovine ratio }\end{array}$ \\
\hline
\end{tabular}

PCA allowed in the first instance to reduce the number of variables from 34 to 16 . Several runs of PCA were performed and in each case those variables that determined low values in the KMO index and the Bartlett test did not contribute to an explanation of the observed variance and they were discarded.

Nineteen variables were excluded because these variables are correlated and/or interact by generating another variable of greater importance or visualization. In this study, the soil type variables, soil degradation, and surface slope, which are synthesized in the productivity variable of natural grassland, were highlighted as examples of excluded variables. Other excluded variables possibly responded to the homogeneity of the producers regarding that variable; for example, the experience in the activity, experience in droughts and the relation between the purchase and sale prices.

The first four components captured $69 \%$ of the system variance, composed of 16 variables (Table 2).

Table 2. Principal components for the importance of each variable in vulnerability to drought

\begin{tabular}{lllll}
\hline Variables & PC1 & PC2 & PC3 & PC4 \\
\hline livestock stocking level' adjustment & 0.806 & 0.116 & 0.186 & 0.131 \\
establishment's size & 0.781 & -0.103 & 0.128 & 0.082 \\
access to technical assistance & 0.715 & 0.385 & 0.036 & 0.088 \\
herd management & 0.668 & 0.111 & 0.246 & 0.012 \\
natural grassland productivity & 0.647 & 0.316 & 0.244 & 0.222 \\
availability of other incomes & 0.089 & 0.843 & -0.100 & -0.047 \\
availability of savings for investing in the farm & 0.264 & 0.734 & 0.148 & 0.083 \\
public policies access & 0.028 & 0.614 & 0.358 & 0.231 \\
strong commercial links with nearby producers & -0.093 & 0.608 & 0.549 & 0.242 \\
fodder production & 0.239 & 0.144 & 0.874 & -0.154 \\
availability of land to produce fodder & 0.365 & -0.085 & 0.756 & 0.244 \\
access to supplements and rations & 0.103 & 0.438 & 0.489 & 0.280 \\
possibility of leasing land at critical times & 0.363 & 0.381 & 0.488 & 0.097 \\
access to productive credits & 0.327 & -0.130 & 0.275 & 0.812 \\
commercial flexibility for purchase/ sale of cattle & 0.236 & 0.340 & -0.104 & 0.784 \\
lack of investment capacity in the farm & 0.523 & -0.246 & -0.134 & 0.594 \\
\hline Proportion & $\mathbf{3 5 . 4 2 7}$ & $\mathbf{1 5 . 6 2 6}$ & $\mathbf{9 . 2 8 9}$ & $\mathbf{8 . 6 6 9}$ \\
Cumulative & $\mathbf{3 5 . 4 2 7}$ & $\mathbf{5 0 . 0 5 3}$ & $\mathbf{5 9 . 3 4 2}$ & $\mathbf{6 8 . 0 1 1}$ \\
\hline
\end{tabular}


The first component explained $35.4 \%$ of the variance and can be defined as the ability of producers to manage cattle activity. It was strongly correlated with the livestock stocking level adjustment, the dimensions of the establishment, the access to technical assistance, herd management, and natural grassland productivity.

The second component represents the socio-economical ability to cope with drought and explained $15.7 \%$ of the variance. The component was related to the availability of other incomes, the availability of savings for investing in the establishment, public policies access and the presentation of strong commercial links with nearby producers.

The third component, the capacity to generate/the ability to access alternatives sources of cattle feeding in critical times, explained $9.3 \%$ of the system variance. This component was defined by fodder production (without considering natural grassland), the availability of arable land to produce fodder, the access to supplements and rations, and the possibility of leasing land at critical times.

Finally, the fourth component referred to the capacity and financial flexibility of each producer and explained $8.7 \%$ of the variance. This component was related to the ability to access productive credits, commercial flexibility for the purchase and sale of cattle and the lack of investment capacity in the establishment.

\subsection{Producer Groups}

From the previously identified components, it was possible to group cattle producers into 7 groups (Figure 3 ) that represent significant differences according to their relations of dissimilarity $(\mathrm{rA}=0.91 ; \mathrm{p}<0.001)$. Only the differences between group $\mathrm{N}^{\circ} 4$ (the group with one producer) and the remaining groups were not significant.

Group $\mathrm{N}^{\circ} 1$ of the producers was integrated by 10 producers, in which the first three components presented the lowest values. The fourth component of group $\mathrm{N}^{\circ} 1$ barely exceeded the $\mathrm{N}^{\circ} 2$ group of producers (Figure 4). Common features of these groups include that these were small producers with an almost exclusive management of natural grassland, with a limited ability to access to credit and help, and little financial margin for implementing alternatives.

Group $\mathrm{N}^{\circ} 2$ included producers with low values in four of the components. When compared to the other producers, lower values were related to components 2 and 4 (Figure 4). This corresponded with cattle family producers who managed small sized farms, who could access public policies and had good commercial relations with their neighbours. These producers presented a low saving capacity and did not have non-farm incomes. They did not own significant surface for fodder production, but in critical times, they could implement the purchase of rations. They showed limited financial capacity and little flexibility to carry out commercial transactions in critical situations.

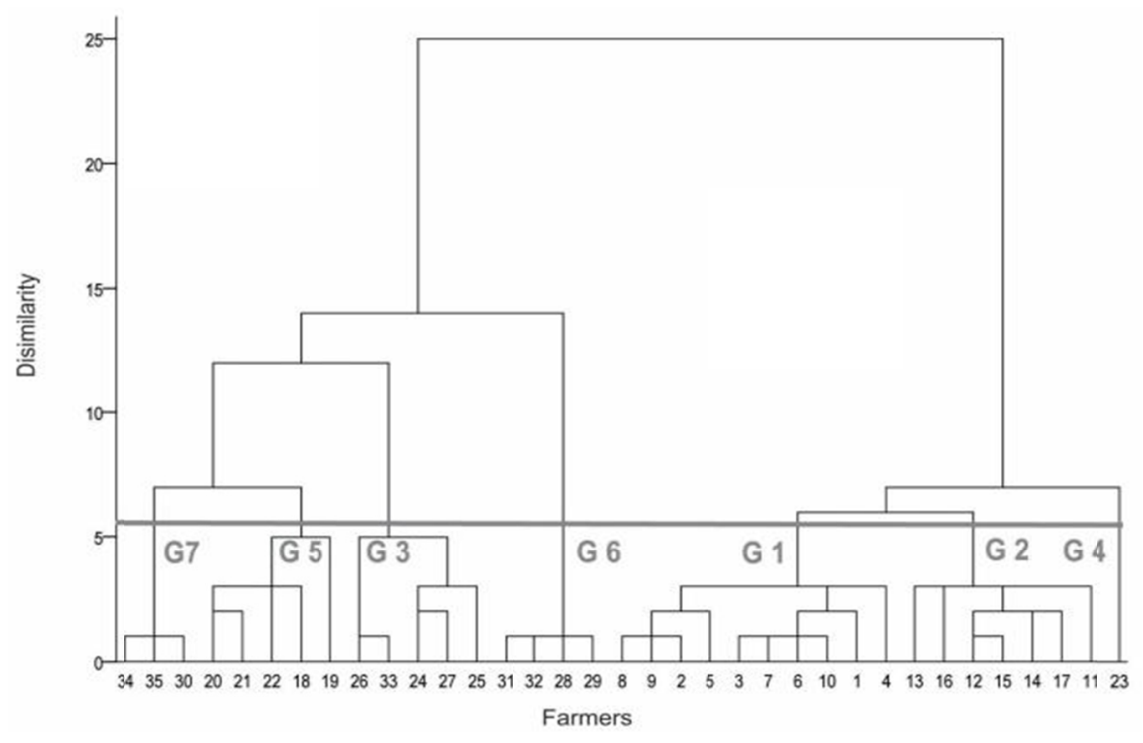

Figure 3. Dendrograms of the 35 cattle producers according to into the response capacity to drought 
The producers in Group $\mathrm{N}^{\circ} 3$ showed high values in components 1,3 and 4 and medium values in component 2 (Figure 4). These producers managed medium and large farm sizes, with good herd management and an adjusted livestock stocking level, and had non-farm incomes or had strong links with their neighbours. In general, producers who had non-farm incomes managed larger areas and did not relate with neighbour producers, and vice versa. Due to these exclusive features, values in component 2 were medium. Producers in this group had good production or fodder purchase possibilities and had good financial capacity.

Group N 4 included only one producer. This producer was a non-conventional cattle producer who raised cattle as a complementary marginal activity, managed a small surface area and was an employee in the services sector.

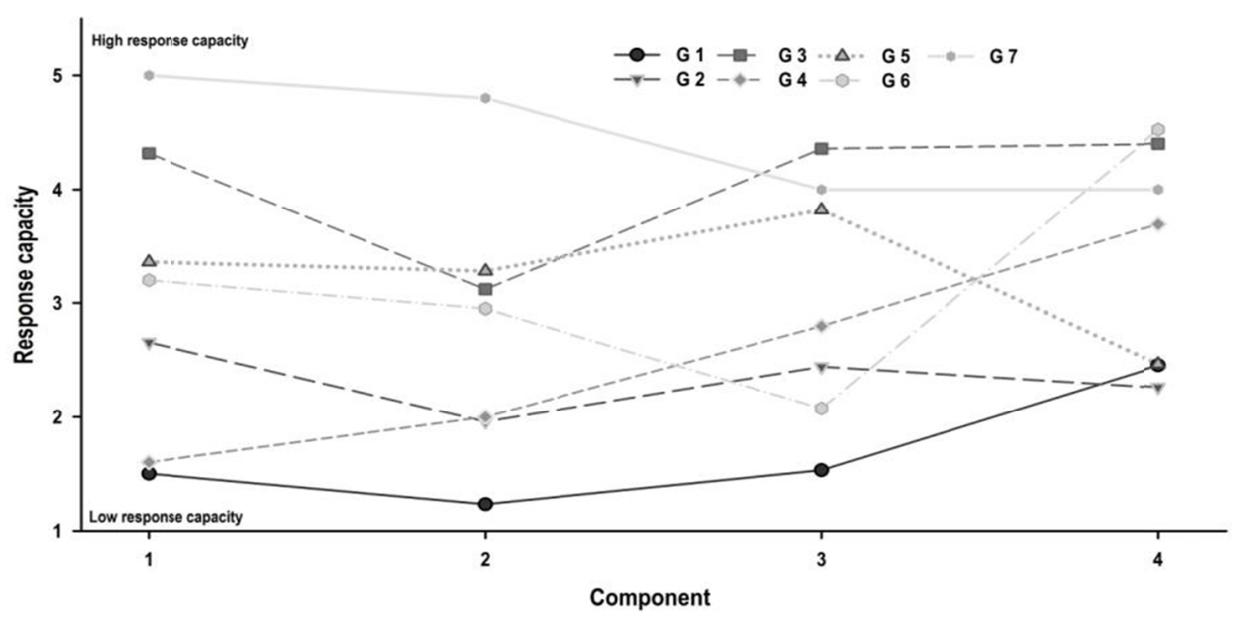

Figure 4. Medium values of each producer group according to the PCA

The $\mathrm{N}^{\circ} 5$ group of producers presented medium to high values in the three first components and a low value in the last one (Figure 4). They were medium and large producers, with good herd management and high fodder production and had non-farm incomes or access to public policies. Additionally, these producers had a good relation with nearby producers and medium financial capacity. They showed very low commercial capacity, principally due to difficulties in releasing the cattle in hydric stress moments.

The producers in group $\mathrm{N}^{\circ} 6$ showed medium values in components 1 and 2 , low values in component 3 , and very high values in component 4 . This group included producers who managed a small size farm but had an adjusted livestock stocking level and constant technical assistance. For these producers, cattle raising was not their main activity, which implied lower dependence. Moreover, they had the possibility to access non-farm incomes, a larger investing capacity, and commercial flexibility. This group included producers with degrees in agrarian training and those who did not reside constantly on the property.

Finally, the producers in group $\mathrm{N}^{\circ} 7$ showed very high values in components 1 and 2 and high values in components 3 and 4 . This group was integrated by producers who managed a large sized farm, with an adjusted livestock stocking level, property and non-property incomes, and financial margin for the search of alternatives. In moments of hydric stress, these producers usually did not have problems accessing complements and rations. Additionally, due to their producing farm size, they presented large surfaces for fodder production.

It is worth noting those groups 1, 2 and 4 (51\%) present values of response capacity well below those acceptable and that only groups 3 and 7 (25\%) present values close to a high response capacity.

The hierarchization made by the producers on the importance of each variable in the explanation of vulnerability to drought was not associated with the state of their situation. As a result, the correlations in the variables importance and the state of their situation were not significant $(p>0.05)$.

\section{Discussion}

The proposed approach identified a group of variables that determined four components associated with response groups to minimize drought vulnerability. These response groups were defined by physical, economic-financial, productive, and socio-cultural variables, reinforcing the idea that drought and the vulnerability to drought are multidimensional complex processes (Wilhelmi \& Wilhite, 2002; Blaikie et al., 1994). This set of variables 
determined 4 components that were associated with groups of responses to reduce vulnerability to drought. According to the importance assigned by the producers, the groups were organized into the capacity for cattle management, the socio-economic capacity to handle drought, the capacity to generate alternatives to cattle feeding, and the commercial and financial flexibility of the producers. These groups did not have a direct correlation with the classic sensitivity and adaptive capacities or with the classical dimensions under which the variables of the socio-environmental systems are usually classified. The vast majority of producers identified that their state of affairs would prevent them from being able to appropriately respond to a drought. In addition, the producer's state of affairs was not associated with the ability to identify response capacities. Our results determined 7 groups of producers that had different characteristics. These differing characteristics were in regards to the state of the situation with respect to the groups of response necessary to face the drought. The heterogeneity identified among the producers suggested that the management unit for the implementation of public policies in Uruguay presented weaknesses.

The methodology used presented similarities with the approaches made by Marshall et al. (2014), and Usai et al. (2006). Unlike the first approach, in this work, the variables were not predetermined, and unlike both approaches, the identification of the variables was performed according to the importance assigned to each variable by the producers. In both cases, the information used referred to the state of the situation of the producers; information that was used in this work to identify groups of producers and to prioritize the capacities to be developed by each group of producers.

The first component corresponded to the capacity to manage cattle activity, central capacity of structural shape, and particularly to climatic non-favourable situations. In this component, the variable of livestock stocking level is highlighted. It is a determinant variable of the gross value of production (McKeon et al., 2009; O'Reagain et al., 2014), of sustainability and viability of livestock establishment (Foran \& Stafford Smith, 1991; Johnston et al., 2000), and of the system's vulnerability (Dieguez Cameroni et al., 2014). This is strongly related to variables, herd management, and the production of the natural grassland, and therefore it presents a central role in component 1 . The addition of this capacity is possible through the implementation of a series of technological changes of low relative costs that could be utilized by a large number of producers.

The second component, which establishes the socio-economic capacity to face drought, determined the strategies identified by the producers and referred to the factors and economic resources to appeal to during critical times. This capacity is essential in livestock systems because it refers to diversity and the possibility of alternative ways to face threats. This strategies group adjusts to the first block of variables identified by Chapin et al. (2009) about adaptive capacity because economic and cultural diversity provides the basis for adjusting to change. The first two variables highlight the importance of incomes to generate savings that may be invested on the property, and the importance of public policies owing to their contention role in times of crisis (McKeon et al., 2009). Additionally, and as stated by Chapin et al. (2010), due to their importance by innovation, incentives contribute to the economic and productive diversification and increase adaptability. The other two values refer to the linking and integration that producers present to, or between, agricultural organizations. Producers with higher levels of formal and/or informal integration generally have more access to information and exchange, more access to public policies, and potentially higher commercial links and benefits due to mutual cooperation between each other. In these response groups, the producers with the higher capacity would be better positioned to handle drought events.

The third component highlights food complementation alternatives, which are often used in extensive cattle systems. This component is very important as food demand frequently exceeds the supply during drought periods. Therefore, increasing the capacity to access livestock food sources is important for most agricultural establishments. In the first instance, in-property alternatives related to storage and production within the establishment stand out. In this meaning, Mosnier et al. (2009) propose that fodder storage is a mitigation decision of important relevance for producers. They also show the alternatives that imply market transactions are associated with the purchase of food. This alternative presents the risk associated with drought length and intensity (Gillard \& Monypenny, 1990), which will determine increases in the volume of food to be bought.

The fourth component refers to financial and commercial flexibility. This component is of great importance in order to respond to external threats, particularly to drought events. This component is mainly highlighted as a frequent strategy strongly linked to cattle sale in drought periods to decrease land pressure. Gillard and Monypenny (1990) propose that a livestock sale (when pricing is fair) is the best commercial option, as the duration of drought events is unknown. 
The identified components did not correlate directly with classic exposition, sensitivity, and adaptive capacity components, as defined by Chapin et al. (2009), and McCarthy et al. (2001). Nor did they correlate with the classical dimensions of the socio-ecological systems. In our study, the components may be interpreted as wider capacities that allow for the understanding and strengthening of the response capacities to drought events. In this approach, the response capacity was understood in a broader way than the response proposed by McCarthy et al. (2001), and Chapin et al. (2009) about adaptive capacity and integrated the totality of actions to be implemented (intensify or improve) to reduce the exposition or sensitivity or to increase the adaptation.

The identified components were consistent with the actual extensive cattle industry context in Sierras del Este and with the response capacities to face drought by producers. The identified components were interpreted as large response groups from which to define alternatives to respond to differential vulnerability situations between producers to drought events.

From the identified response groups and the differences between the producers from the study area, it was possible to classify the totality of cattle producers into 7 groups, according to each group's situation and need to decrease vulnerability.

The $\mathrm{N}^{\circ} 1$ group of producers presented very low values in every response group. Thus, it was the group with most need to strengthen their capacities in order to reduce vulnerability because it is required to strengthen the totality of all groups. Low values generated a resilient situation of high stability, which does not allow moving to a lower vulnerability scenario. The few possibilities to generate adaptive and response capacities determine that they also cannot generate an alternative to reduce sensitivity.

The $\mathrm{N}^{\circ} 2$ group of integrated producers that, according to the scheme proposed by Chapin et al. (2009), show some level of development of adaptive capacity due to their access to public policies and links with their neighbours. However, these are producers that are highly affected by droughts. This finding is associated with the savings/capitalization capacity: after favourable productive years (high incomes), these producers carry out the purchase of cattle to increase the herd. This situation determines that during times of drought, the livestock stocking level is higher than what the property can hold and it becomes necessary to appeal to the incorporation of other food sources or to decrease the herd size. Additionally, this context generates a highly complex scenario associated with overgrazing, a situation that, as was highlighted for other regions by Thomas (2008), compromises the system and also decreases the productivity for the following periods. These producers' situations suggest that the development of specific adaptive strategies is not sufficient to decrease the system sensitivity. This responds to the significance and stability of the variable adjustment of the livestock stocking level, which is the key variable in the livestock activity.

Groups $\mathrm{N}^{\circ} 3$ and $\mathrm{N}^{\circ} 7$ included the producers with smaller drought vulnerability levels. The common feature is that these producers managed medium to large farm sizes, they had non-farming incomes and, most likely as a result of a scale economy, they showed adjusted livestock stocking level and carried out better farm management. Except for the producers in group $\mathrm{N}^{\circ} 2$, who had a very low socio-economic capacity to face drought, the remainder of the producers did not integrate the priority producer's line for the implementation of public policies. Further study of the practices done by these producers is warranted in order to evaluate if it is possible and profitable for implementation by the cattle family producers and smallholders.

The producers in group $\mathrm{N}^{\circ} 5$ had medium values in the first 3 response groups and low values in the fourth. This shows the difficulty of some producers to sell cattle in times of crisis and highlights the low adaptive capacity of some producers to anticipate the severity of drought events and the difficulty (and denial) of these producers to release part of their capital. These situations determine that producers who come to terms with livestock selling do it too late, with economic consequences. Livestock selling is highlighted as an alternative to reinforcing the response capacity in this last component or to improving the management of activity or fodder production, which may minimize the impact of the commercial strategy adopted in drought events.

The producers in group $\mathrm{N}^{\circ} 6$ did not have cattle raising as a principal item and showed the lowest values in response group 3. The commercial strategy of these producers determined that they focused on the managements of a small-scale farm with a low livestock stocking level. These groups had a medium vulnerability level that offset this situation with flexibility from their non-farming incomes. Additionally, they reduced their vulnerability via their high adaptive capacity related to constant technical assistance and adjusted livestock stocking level, which determined a lower level of vulnerability in this group.

As highlighted by Campbell et al. (2006), and Marshall and Smajgl (2013), it is very improbable that only one strategy may offer solutions for all producers. In the same way Cros et al. (2004) proposes that success is more likely if a number of strategies are considered. The proposed approach in our study and the definition of response 
groups, and not of key variables, supports this point. The productive, economic, and cultural heterogeneity of producers in the study area will result in different responses.

On the other hand, the variables that determine each response group present diverse associations and intense interrelations. In some occasions, one variable can partially or totally replace another within the same group (i.e., greater fodder production results in less fodder purchasing) or even from another group (i.e., high grassland productivity results in the decrease of fodder purchasing). This situation reinforces the need to increase the set of strategies to reduce vulnerability.

The alternatives related to the implementation of responses determine different dependence levels according to the group of producers and the specific variables to manage. For example, the situation of the alternatives related to response groups 1 and 3 is presented. Response group 1 shows a clear connection with herd management and available farm size. Producers who manage larger surfaces have greater access to technical assistance and have better adjustments in the livestock stocking level, possibly due to an economy of scale strategy. In a drought event, this situation positions smaller producers into a higher vulnerability level due to two factors: an inaccurate livestock stocking level and lower incomes. Therefore, increasing the response capacity of smallholders must be related to strengthening the remaining variables of the response group. In this way, the search of alternatives must focus on improving farm management and in the adjustments of the livestock stocking level to maximize productivity and avoid compromising the natural system. As highlighted by Chapin et al. (2009), this situation would allow for other regions to be less vulnerable to drought events and obtain larger benefits in non-drought periods.

Maintaining the adjusted livestock stocking level would not only contribute to the conservation of the natural grassland and natural resources but also be economically beneficial (Gillard \& Monypenny, 1990). Identified by an important number of producers, overgrazing in drought events becomes a problem, where feeding alternatives tend to be economically nonviable and technically difficult. This situation determines that the sale of livestock at very low prices occurs frequently and is a problem for diverse contexts (McKeon et al., 2009), particularly for our study area. The 1 and 2 groups of producers presented a challenge for the adjustment of livestock stocking levels and the improvement of herd management. For group 5, even though these producers are in a much more favourable position, their possibilities of improvement are related to better herd management. For group 6, smallholders with important non-farm incomes, clear alternatives related to this component were not highlighted because the management is generally appropriate. The values that are not high in this component are related to the fact that livestock was not their principal income and the farm size managed was small.

Increasing the capacity in response group number 1 will have repercussions for the rest of the response groups. During drought events, the improvement of the livestock management would result in less maladjustment between the supply and demand of food, and there would be a lower need for alternative ways to access these. Consequently, increasing the response capacity of group 1 would result in a decreased effort for the generation of capacities of response group 3 .

In the case of response group 3, two variables were highlighted related to the internal capacity to the property, and the remaining two variables related to the search of solutions outside the property (access to rations and complements, and the possibility to lease in critical times). These two variables sub-sets may be understood as complementary and at the same time substitutive, and they present a clear difference according to their linking with the market and therefore with the creation of external dependence. Increasing the response capacity implies that the group may reduce their vulnerability by searching for alternatives. The consolidation of strategies depends on the market dynamic and increases the system's exposure; therefore, it positions the system in a high level of vulnerability. Thus, it is important to know the linkages between variables and components, so the generation of a response in one component does not increase the exposure or sensitivity of others. Even though it is accepted that the vulnerability can be reduced by reducing exposure and sensitivity or increasing the adaptive capacity (Chapin et al., 2010, 2009; McCarthy et al., 2001), it is possible that the identified strategies to reduce a variable may have repercussions by increasing others.

The implementation of changes in livestock management, or in the commercial and financial management of the establishment, generates a great challenge due to the cultural characteristics of the producers in the studied area. Moving forward is a possible strategy for the small livestock producers with high drought vulnerability levels. The acceleration and increase of collective learning is a large challenge in livestock systems (Dieguez Cameroni et al., 2014).

Additionally, increasing the access to public policies, developing and strengthening rural extension programmes, and promoting the linkage and association of producers becomes essential for the consolidation and 
implementation of responses. This group of actions is part of the strategies to increase the adaptive capacity proposed by (Chapin et al., 2009).

\section{Conclusions}

We presented a simple alternative approach for the identification of the level of vulnerability of livestock producers through an operational methodology. This approach proposes that the differential values of sensitivity and exposure determine that the response strategies must be different. The identification and analysis of response capacities must be developed to cope with drought.

We detected 16 variables with a high incidence in the vulnerability of the cattle producers to drought, which defined 4 response groups. All the producers were subsequently classified into 7 groups according to the state of their situation values in the 4 response groups required to cope with the drought.

The composition of 7 groups revealed the heterogeneity of the producers' situation and questioned the current definition of vulnerability and the delimitation of homogeneous regions by public policies in Uruguay.

Vulnerability assessments are the basis for developing strategies to reduce vulnerability to drought, and identifying heterogeneity through producer groups represents the first step in adjusting public policies according to local and specific needs of producers.

\section{Acknowledgements}

We express our gratitude to Emilia Isasa and Ana Laura Mello, who contributed to achieve the manuscript. Also, we thank the cattle producers who participated in the interviews. This research has been carried out with financial support from the Comisión Académica de Posgrado - Universidad de la República (Uruguay).

\section{References}

Abson, D. J., Dougill, A. J., \& Stringer, L. C. (2012). Using Principal Component Analysis for information-rich socio-ecological vulnerability mapping in Southern Africa. Applied Geography, 35(1-2), 515-524. https://doi.org/10.1016/j.apgeog.2012.08.004

Adger, W. N. (2006). Vulnerability. Global Environmental Change, 16(3), 268-281. https://doi.org/10.1016/ j.gloenvcha.2006.02.006

Anderberg, M. (1973). Cluster Analysis for Applications (Vol. 19). Academic, New York.

Andersen, E., Elbersen, B., Godeschalk, F., \& Verhoog, D. (2007). Farm management indicators and farm typologies as a basis for assessments in a changing policy environment. Journal of Environmental Management, 82(3), 353-362. https://doi.org/10.1016/j.jenvman.2006.04.021

Antwi-Agyei, P., Fraser, E. D. G., Dougill, A. J., Stringer, L. C., \& Simelton, E. (2012). Mapping the vulnerability of crop production to drought in Ghana using rainfall, yield and socioeconomic data. Applied Geography, 32(2), 324-334. https://doi.org/10.1016/j.apgeog.2011.06.010

Aryal, S., Cockfield, G., \& Maraseni, T. N. (2014). Vulnerability of Himalayan transhumant communities to climate change. Climatic Change, 125(2), 193-208. https://doi.org/10.1007/s10584-014-1157-5

Blaikie, P., Terry, C., Ian, D., \& Ben, W. (1994). At Risk: Natural Hazards, People's Vulnerability, and Disasters. Human Ecology, 24(1), 141-145. https://doi.org/10.4324/9780203428764

Campbell, B. M., Gordon, I. J., Luckert, M. K., Petheram, L., \& Vetter, S. (2006). In search of optimal stocking regimes in semi-arid grazing lands: One size does not fit all. Ecological Economics, 60(1), 75-85. https://doi.org/10.1016/j.ecolecon.2006.05.010

Cardona, O. D. (2003). The Need for Rethinking the Concepts of Vulnerability and Risk from a Holistic Perspective: A Necessary Review and Criticism for Effective. In G. Bankoff, D. Hilhorst, \& G. Frerks (Eds.), Mapping vulnerability: Disasters, development and people (Chapter 3, pp. 37-51). Taylor \& Francis Group, London. https://doi.org/10.4324/9781849771924

Chapin, F. S., Carpenter, S. R., Kofinas, G. P., Folke, C., Abel, N., Clark, W. C., ... Swanson, F. J. (2010). Ecosystem stewardship: Sustainability strategies for a rapidly changing planet. Trends in Ecology and Evolution, 25(4), 241-249. https://doi.org/10.1016/j.tree.2009.10.008

Chapin, F. S., Kofinas, G. P., \& Folke, C. (2009). Principles of Ecosystem Stewardship: Resilience-Based Natural Resource Management in a Changing World. Springer-Verlag, New York. https://doi.org/10.1007/ 978-0-387-73033-2

Clarke, K. R. (1993). Non-parametric multivariate analyses of changes in community structure. Australian 
Journal of Ecology, 18(1988), 117-143. https://doi.org/10.1111/j.1442-9993.1993.tb00438.X

Cros, M. J., Duru, M., Garcia, F., \& Martin-Clouaire, R. (2004). Simulating management strategies: The rotational grazing example. Agricultural Systems, 80(1), 23-42. https://doi.org/10.1016/j.agsy.2003.06.001

Cruz, G., Baethgen, W., Picasso, V., \& Terra, R. (2014). Análisis de sequías agronómicas en dos regiones ganaderas de Uruguay. Agrociencia Uruguay, 18(1), 126-132.

DIEA. (2011). Censo General Agropecuario. Resultados definitivos. Montevideo. Retrieved from http://www.mgap.gub.uy/portal/hgxpp001.aspx?7,5,786,O,S,0

DIEA. (2016). Anuario Estadístico Agropecuario. Montevideo. Retrieved from http://www.mgap.gub.uy/unidadejecutora/oficina-de-programacion-y-politicas-agropecuarias/publicaciones/anuarios-diea/anuario2016

Dieguez Cameroni, F. J., Terra, R., Tabarez, S., Bommel, P., Corral, J., Bartaburu, D., ... Grosskopf, H. M. (2014). Virtual experiments using a participatory model to explore interactions between climatic variability and management decisions in extensive grazing systems in the basaltic region of Uruguay. Agricultural Systems, 130, 89-104. https://doi.org/10.1016/j.agsy.2014.07.002

Downing, \& Bakker, K. (2000). Drought discourse and vulnerability. In D. A. Wilhite (Ed.), Drought: A Global Assessment, Natural Hazards and Disaster. UK: Routledge Publishers.

Foran, B. D., \& Stafford Smith, D. M. (1991). Risk, biology and drought management strategies for cattle stations in central Australia. Journal of Environmental Management, 33(1), 17-33. https://doi.org/10.1016/ S0301-4797(05)80045-3

Füssel, H.-M. (2007). Vulnerability: A generally applicable conceptual framework for climate change research. Global Environmental Change, 17(2), 155-167. https://doi.org/10.1016/j.gloenvcha.2006.05.002

Füssel, H.-M., \& Klein, R. (2006). Climate change Vulnerability Assessment: An Evolution of Conceptual Thinking. Climate Change, 75(3), 301-329. https://doi.org/10.1007/s10584-006-0329-3

Gallopín, G. C. (2006). Linkages between vulnerability, resilience, and adaptive capacity. Global Environmental Change, 16(3), 293-303. https://doi.org/10.1016/j.gloenvcha.2006.02.004

Gazzano, I., Altieri, M. A., Achkar, M., \& Burgueño, J. (2015). Holistic Risk Index: A Case Study of Cattle Producers in the Protected Area of Farrapos Estuaries-Uruguay. Agroecology and Sustainable Food Systems, 39(2), 209-223. https://doi.org/10.1080/21683565.2014.967439

Gbetibouo, G. A., \& Ringler, C. (2009). Mapping South African Farming Sector Vulnerability to Climate Change and Variability: A Subnational Assessment (pp. 1-27). Amsterdam Conference on the Human Dimensions of Global Environmental Change "Earth System Governance: People, Places and the Planet". International Food Policy Research Institut.

Gillard, P., \& Monypenny, R. (1990). A decision support model to evaluate the effects of drought and stocking rate on beef cattle properties in Northern Australia. Agricultural Systems, 34(1), 37-52. https://doi.org/ 10.1016/0308-521X(90)90092-5

Hahn, M. B., Riederer, A. M., \& Foster, S. O. (2009). The Livelihood Vulnerability Index: A pragmatic approach to assessing risks from climate variability and change-A case study in Mozambique. Global Environmental Change, 19(1), 74-88. https://doi.org/10.1016/j.gloenvcha.2008.11.002

Johnston, P. W., McKeon, G. M., Buxton, R., Cobon, D., Ken, D., Hall, W., \& Scanlan, J. (2000). Managing Climatic Variability in Queensland's Grazing Lands-New approaches. In G. Hammer, N. Mitchell, \& C. Nicholls (Eds.), Applications of Seasonal Climate Forecasting in Agricultural and Natural Ecosystems-The Australian Experience (pp. 197-226). Dordrecht, The Netherlands: Kluwer Academic Press. https://doi.org/10.1007/978-94-015-9351-9_14

Luers, A. L. (2005). The surface of vulnerability: An analytical framework for examining nvironmental change. Global Environmental Change, 15, 214-223. https://doi.org/10.1016/j.gloenvcha.2005.04.003

Marshall, N. A., \& Smajgl, A. (2013). Understanding Variability in Adaptive Capacity on Rangelands. Rangeland Ecology \& Management, 66(1), 88-94. https://doi.org/10.2111/REM-D-11-00176.1

Marshall, N. A., Stokes, C. J., Webb, N. P., Marshall, P. A., \& Lankester, A. J. (2014). Social vulnerability to climate change in primary producers: A typology approach. Agriculture, Ecosystems and Environment, 186, 86-93. https://doi.org/10.1016/j.agee.2014.01.004

McCarthy, J. J., Canziani, O. F., Leary, N. A., Dokken, D. J., \& White, D. J. (2001). Climate Change 2001: 
Impacts, Adaptation, and Vulnerability, Contribution of Working Group II to the Third Assessment Report of the Intergovernmental Panel on Climate Change. Cambridge: Cambridge University Press.

McKeon, G. M., Stone, G. S., Syktus, J. I., Carter, J. O., Fraser, G., W., Crimp, S. J., \& Howden, S. M. (2009). Climate change impacts on northern Australian rangeland livestock carrying capacity: A review of issues. Rangeland Journal, 31(1), 1-29. https://doi.org/10.1071/RJ08068

Moser, S. C., \& Ekstrom, J. A. (2010). A framework to diagnose barriers to climate change adaptation. Proceedings of the National Academy of Sciences, 107(51), 22026-22031. https://doi.org/10.1073/pnas.1007 887107

Mosnier, C., Agabriel, J., Lherm, M., \& Reynaud, A. (2009). A dynamic bio-economic model to simulate optimal adjustments of suckler cow farm management to production and market shocks in France. Agricultural Systems, 102(1-3), 77-88. https://doi.org/10.1016/j.agsy.2009.07.003

O’Brien, K., Leichenko, R., Kelkar, U., Venema, H., Aandahl, G., Tompkins, H., ...West, J. (2004). Mapping vulnerability to multiple stressors: Climate change and globalization in India. Global Environmental Change, 14(4), 303-313. https://doi.org/10.1016/j.gloenvcha.2004.01.001

O'Reagain, P., Scanlan, J., Hunt, L., Cowley, R., \& Walsh, D. (2014). Sustainable grazing management for temporal and spatial variability in north Australian rangelands-A synthesis of the latest evidence and recommendations. Rangeland Journal, 36(3), 223-232. https://doi.org/10.1071/RJ13110

OPYPA. (2009). Comportamiento del sector carne vacuna en 2009 y perspectivas en 2010. Montevideo.

OPYPA. (2016). Análisis sectorial y cadenas productivas. Temas de política. Montevideo.

Pandey, R. (2010). Heterogeneity in Household Characteristics, Forest Resource Utilization and Sustainability in Hills of Uttaranchal: A Case Study. Silva Lusitana, 18(1), 75-84.

R-Team. (2012). $R: A$ language and environment for statistical computing $R$ Foundation for StatisticalComputing. Retrieved from http://www.r-project.org

Soares, M. B., Gagnon, A. S., \& Doherty, R. M. (2012). Conceptual elements of climate change vulnerability assessments: A review. International Journal of Climate Change Strategies and Management, 4(1), 6-35. https://doi.org/10.1108/17568691211200191

Soriano, A. (1991). Río de la Plata Grasslands. In R. T. Coupland (Ed.), Natural grasslands: Introduction and Western Hemisphere (pp. 367-407). Amsterdam: Elsevier.

Sullivan, C. A. (2011). Quantifying water vulnerability: A multi-dimensional approach. Stochastic Environmental Research and Risk Assessment, 25(4), 627-640. https://doi.org/10.1007/s00477-010-0426-8

Thomas, R. J. (2008). Opportunities to reduce the vulnerability of dryland farmers in Central and West Asia and North Africa to climate change. Agriculture, Ecosystems and Environment, 126(1-2), 36-45. https://doi.org/ 10.1016/j.agee.2008.01.011

Usai, M. G., Casu, S., Molle, G., Decandia, M., Ligios, S., \& Carta, A. (2006). Using cluster analysis to characterize the goat farming system in Sardinia. Livestock Science, 104(1-2), 63-76. https://doi.org/ 10.1016/j.livsci.2006.03.013

Wilhelmi, O. V., \& Wilhite, D. A. (2002). Assessing vulnerability to agricultural drought: A Nebraska case study. Natural Hazards, 25(1), 37-58. https://doi.org/10.1023/A:1013388814894

Zarafshani, K., Sharafi, L., Azadi, H., Hosseininia, G., De Maeyer, P., \& Witlox, F. (2012). Drought vulnerability assessment: The case of wheat farmers in Western Iran. Global and Planetary Change, 98-99, 122-130. https://doi.org/10.1016/j.gloplacha.2012.08.012

\section{Copyrights}

Copyright for this article is retained by the author(s), with first publication rights granted to the journal.

This is an open-access article distributed under the terms and conditions of the Creative Commons Attribution license (http://creativecommons.org/licenses/by/4.0/). 